\title{
Midgut Loop
}

National Cancer Institute

\section{Source}

National Cancer Institute. Midgut Loop. NCI Thesaurus. Code C34211.

The portion of the midgut in the developing embryo that bends around the superior

mesenteric artery to form the alimentary canal from the duodenum through the proximal two-thirds of the transverse colon. 